\title{
A study on concept of $P$ - drug selection among rural general practitioners
}

\author{
Priyadarshini Bai G. ${ }^{1}$, Ravi Kumar P. ${ }^{2}$
}

${ }^{1}$ Department of Pharmacology,

${ }^{2}$ Department of Pulmonology, Sri Siddhartha Medical College, Tumakuru 572107, India

Received: 01 November 2016 Accepted: 29 November 2016

\section{*Correspondence to:}

Dr. Priyadarshini Bai G., Email:

ravi_darshini@yahoo.co.in

Copyright: () the author(s), publisher and licensee Medip Academy. This is an openaccess article distributed under the terms of the Creative Commons Attribution NonCommercial License, which permits unrestricted noncommercial use, distribution, and reproduction in any medium, provided the original work is properly cited.

\section{ABSTRACT}

Background: The objective of the study was to assess the awareness of P-drug selection among rural general practitioners's (GP) for common medical conditions.

Methods: Fifty general practitioners in Tumakuru district were provided with proformas for selection of $\mathrm{P}$ - drugs for mild to moderate hypertension, diabetes, upper respiratory tract infections and acid peptic disease based on safety, affordability, need, and efficacy (SANE criteria).

Results: Forty one GP's responded by completing the proformas. Seventeen of them were aware of the concept of P- drug selection. In hypertension, beta blockers followed by Angiotensin Converting Enzyme (ACE) inhibitors were most commonly preferred. In diabetes, biguanides followed by sulfonylureas were preferred as oral hypoglycemic agents. Ampicillin, Ciprofloxacin and Cotrimoxazole were the commonly used antibiotics for upper respiratory tract infections. Ranitidine and antacids were preferred for acid peptic disease. Affordability followed by efficacy was the deciding criteria for P- drug selection.

Conclusions: There is lack of awareness of $\mathrm{P}$ - drug selection among many rural GP's. Therefore, there is necessity to create awareness about P-drug selection through continued medical education for rational use of drugs.

Keywords: General practitioners, P- drug, Proforma, Rational use of drugs, SANE criteria

\section{INTRODUCTION}

Medical science in general and therapeutics in particular is undergoing rapid change and the tremendous growth of the pharmaceutical industry has led to the production of many drugs. This makes it complicated for the physician to prescribe drugs rationally. There is an increasing concern regarding inappropriate, irrational, or sometimes even harmful prescribing patterns. ${ }^{1}$ There is a lot of evidence from observational or experimental studies that, eligible patients are not always prescribed the medicines indicated for their condition. On the other side, there is also evidence about over and misuse of pharmaceutical products. A lot of research is trying to analyze and to understand the factors which influence physician prescribing decisions and practice. Thus, it is important to follow the recommended optimal and established drug prescription guidelines for the benefit of the patient as well as society. ${ }^{2}$
There are several factors which influence the prescribing behaviour of physicians. Some factors are modifiable and some others are non-modifiable. The non-modifiable factors do not offer any opportunity for any improvements in prescribing behaviour. For example, the age and sex of the physician or the patient, the type of disease state, the socio-economic characteristics of the practicing area or the reimbursement status of therapy., On the other hand, there are factors which can be influenced and in turn cause a modification to the prescribing behaviour of physicians. Such modifiable factors may be the training and the experience of the physician, various social factors, the number of practitioners in a particular place, the type of environment and others. ${ }^{5-8}$

According to WHO "Rational use of drugs requires that patients receive medications appropriate to their clinical needs, in doses that meet their own individual requirements for an adequate period of time, at the lowest 
cost to them". ${ }^{9}$ In order to prevent serious health risks and socio-economic burden to the patient, WHO has given the Guide to Good Prescribing, which gives a guidance for a structured problem-solved six-step process in choosing and prescribing a suitable drug for an individual patient, i.e., P-drug concept. P- drug referred to as "Preferred" or "Particular" or "Personal" drug is the drug chosen by the physician for a particular disease to treat it in a cost effective manner. ${ }^{10}$ The idea was to make physicians familiar with few $\mathrm{P}$ - drug chosen from national essential drug list, based on efficacy, safety, suitability, and cost, with regard to the population they come across. ${ }^{11}$

This study is conducted to assess the awareness and pattern of P- drug selection among rural general practitioners for medical conditions routinely encountered in general practice.

\section{METHODS}

50 General Practitioners in Tumakuru district were given anonymous proformas for selection of P- drugs for common conditions like Diabetes mellitus, Hypertension, URTI, Peptic ulcer. The proforma designed had the following headings: Diagnosis, Specification of the therapeutic objective, Listing of effective group of drugs, and Selection of an effective drug based on safety, affordability, need, and efficacy (SANE criteria). The physicians were requested to fill the proforma. Data was analyzed using descriptive analysis and results were expressed as percentages.

\section{RESULTS}

Out of 50, Forty one general practitioners (82\%) responded by completing the proformas. Seventeen $(34 \%)$ of them were aware of the concept of P- drug selection. In mild to moderate hypertension, beta blockers (37\%), ACE inhibitors (29\%), Amlodipine (15\%), and thiazides $(13 \%)$ were most commonly preferred as shown in Figure 1.

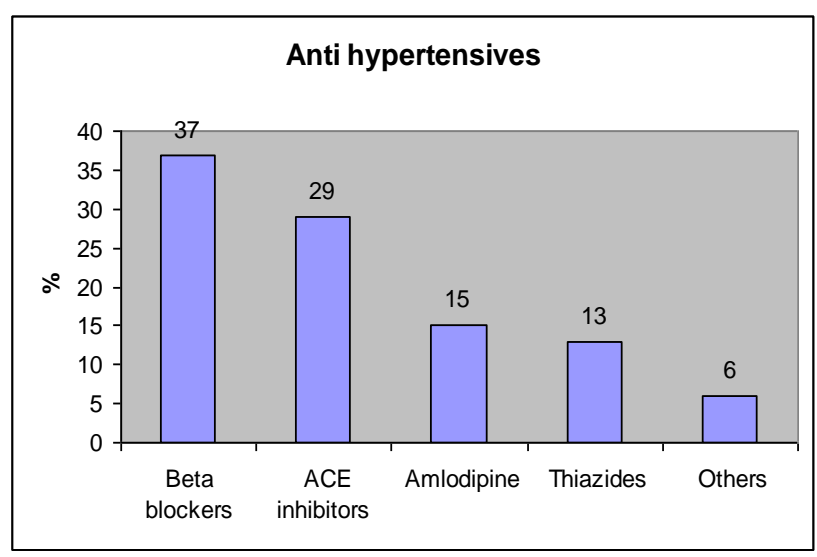

Figure 1: List of drugs used in mild to moderate hypertension.
Figure 1 depicts various antihypertesives preferred by general practitioners.

In uncomplicated diabetes, Metformin (27\%), sulfonylureas $(21 \%)$ and their combination $(43 \%)$ were preferred as oral antidiabetic agents and are shown in Figure 2.

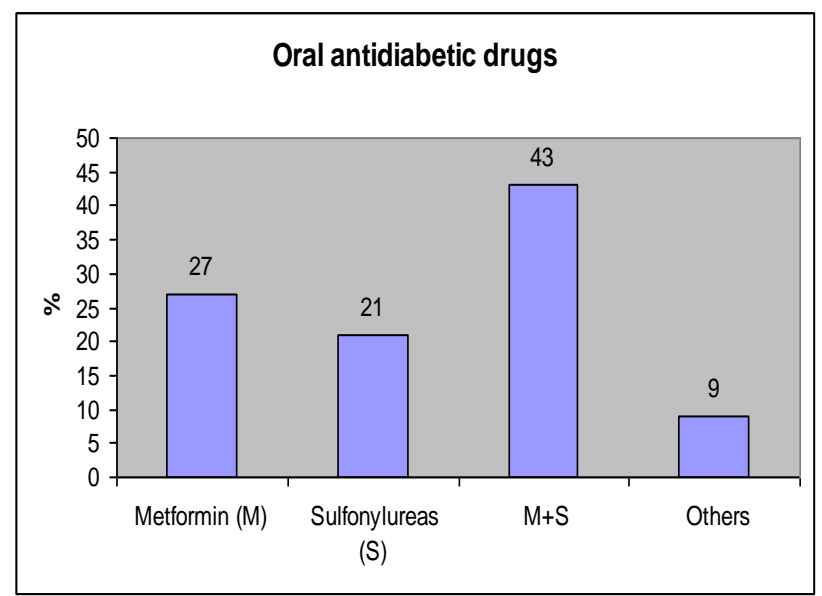

Figure 2: List of oral antidiabetic drugs in type 2 diabetes mellitus.

Figure 2 depicts various antidiabetic drugs preferred by general practitioners.

Ampicillin (28\%), Ciprofloxacin (23\%), Erythromycin (16\%) and Cotrimoxazole (15\%) were the preferred antibiotics for upper respiratory tract infections other than symptomatic treatment and is shown in Figure 3.

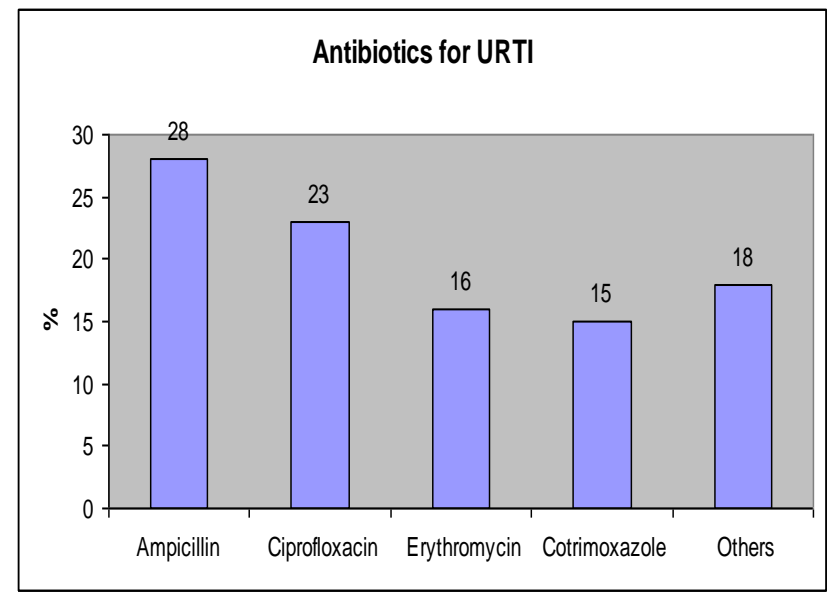

\section{Figure 3: List of oral antibiotics preferred for upper respiratory tract infection (URTI).}

Figure 3 depicts various antibiotics preferred by general practitioners for URTI.

Ranitidine (59\%), Omeprazole (11\%), Pantoprazole (9\%) and antacids $(8 \%)$ were preferred for acid peptic disease as shown in Figure 4. Affordability followed by efficacy 
was the deciding criteria for P- drug selection among these practitioners.

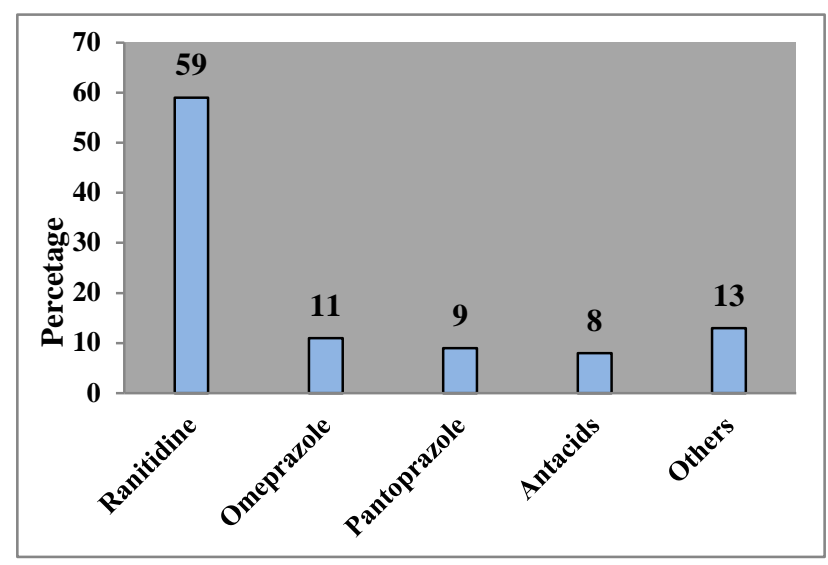

Figure 4: List of antiulcer drugs used in acid peptic disease.

Figure 4 depicts various antiulcer drugs preferred by general practitioners for acid peptic disease.

\section{DISCUSSION}

In the present study, though the majorities of clinicians seem to be aware of and prescribed essential medicines (EM), but surprisingly none of them was able to correctly quantify the drug/drug combinations. The findings are similar to the previous study conducted by Mahajan, et al. $^{12}$

Availability of numerous drugs has lead to an era of "drug explosion". The global drug scenario can thus be considered as "therapeutic jungle". This may lead to irrational prescriptions. Understanding the concept of Pdrugs is essential for rational use of drugs which includes the right drug, given to the right patient, in the right dosage, at the right cost. Rational use of medicines contributes to high-quality health care, while irrational use leads to health hazards and wastage of resources that are already insufficient in the majority of health care systems. ${ }^{13} \mathrm{P}$ - drugs differ from country to country and between doctors due to varying availability and cost of drugs, different national formularies and essential drug lists, medical culture and individual interpretation of information. P- drug selection must not depend on aggressive pharmaceutical marketing as the latest or the most expensive drug may not be the most efficacious and safe one. As evident from the present study, older drugs are preferred as they are cost effective. Newer drugs are less prescribed probably due to lack of information, access and high cost. Concept of P- drug is a relatively new addition to the medical curriculum; hence, most of the senior clinicians may not be aware about it. However, even among junior residents, percentage of practicing P-drug is less though they were exposed to this in their pharmacology curriculum during MBBS. ${ }^{14}$ This indicates that the P-drug concept has remained confined to pharmacology and has not become popular among clinicians. This can be considered as a major cause of errors in prescribing with its adverse consequences subsequently. ${ }^{15-17}$ Involvement of clinicians is vital if the P-drug concept is to succeed. A problem-based learning session for teachers in medical colleges needs to be organized.

\section{ACKNOWLEDGEMENTS}

We would like to thank all the rural general practitioners of Tumakuru district for their immense support and valuable support for conducting this study.

Funding: No funding sources

Conflict of interest: None declared

Ethical approval: The study was approved by the Institutional Ethics Committee of Sri Siddhartha Medical College

\section{REFERENCES}

1. Theodorou M, Tsiantou V, Pavlakis A, Maniadakis N, Fragoulakis V, Pavi E et al. Factors influencing prescribing behaviour of physicians in Greece and Cyprus: results from a questionnaire based survey. BMC Health Serv Res. 2009;9:150.

2. O' Mahony D, Galagher PF. Inapprpriate prescribing in the older population: need for new criteria. Age and ageing. 2008;37:138-41.

3. De Bakker D, Coffie D, Heerdink E, Van Dijk L, Groenewegen P. Determinants of the range of drugs prescribed in general practice: a cross-sectional analysis. BMC Health Services Research. 2007;7:132.

4. Watkins C, Harvey I, Carthy P, Moore L, Robinson E, Brawn R: Attitudes and behavior of general practitioners and their prescribing costs: a national cross sectional survey. Qual Saf Health Care. 2003;12:29-34.

5. Coleman JS, Katz E, Menzel H. Medical Innovation. A diffusion study Indianapolis: The Bobbs-Merril Company Inc; 2000.

6. Ryan M, Yule B, Bond C, Taylor RJ. Scottish general practitioners' attitudes and knowledge in respect of prescribing costs. BMJ. 1990;300:1316-68.

7. Bradley C. Factors which influence the decision whether or not to prescribe: the dilemma facing general practitioners. Br J Gen Pract. 1992;42:454-8.

8. Muijrers P, Grol R, Sijbrandij J, Janknegt R, Knottnerus J. Differences in prescribing between GPs. Impact of the cooperation with pharmacists and impact of visits from pharmaceutical industry representatives. Fam Pract. 2005;22:624-30.

9. World Health Organization. The Rational Use of Drugs. Report of the Conference of Experts. Geneva: WHO; 1985.

10. World Health Organization. Guide to Good Prescribing. Geneva: WHO; 1994. 
11. Singh NR. P-drug concept and the undergraduate teaching. Indian J Pharmacol. 2008;40:285.

12. Mahajan R, Singh NR, Singh J, Dixit A, Jain A, Gupta A. Current scenario of attitude and knowledge of physicians about rational prescription: A novel cross-sectional study. J Pharm Bioallied Sci. 2010;2:132-6.

13. Shivhare SC, Kunjwani HK, Manikrao AM, Bondre AV. Drugs Hazards and Rational Use of Drugs: A Review. J. Chem. Pharm. Res. 2010;2(1):106-12.

14. Patrício KP, Alves NA, Arenales NG, Queluz TT. Teaching the Rational Use of Medicines to medical students: A qualitative research. BMC Med Educ. 2012;12:56.

15. World Health Organization. Factsheet: WHO Policy Perspectives on Medicines-Promoting rational use of medicines: Core components Geneva: WHO; 2002.
Available

from: htpp://www.who.int/entity/medicines/publications/po licyperspectives/ppm05en.pdf. [Last cited on 2013 Dec 20].

16. World Health Organization: Selection and rational use of medicines. Fact sheet: N338, 2010. Available from:

http://www.who.int/mediacentre/factsheets/fs338/en/. [Last cited on 2013 Dec 20].

17. Maxwell S, Walley T, Ferner RE. Using drugs safely. BMJ. 2002;324:930-1.

Cite this article as: Priyadarshini BG, Kumar RK. A study on concept of P-drug selection among rural general practitioners. Int J Basic Clin Pharmacol 2017;6:155-8. 